\title{
Chapter 8: A voice for advancing the profession of teaching?
}

\section{Andy Goodwyn}

\section{Introduction}

It is now a global phenomenon that most education systems have recognised a significant problem in seeking to keep the best teachers in the classroom where they make the biggest difference to students' lives. There are two major issues. Many very good teachers either simply leave the profession, becoming worn down by constant externally imposed changes, or move out of the classroom to take on management roles. A range of countries are trying to tackle this challenge by creating an alternative career structure (Goodwyn, 2016) that provides recognition, status and reward and keeps the teachers working in their own classrooms but also helping to develop other teachers. These authorised teachers can be seen as special representatives of the profession, providing at least one strong voice based on being teachers with true expertise.

In England, The Advanced Skills Teacher scheme that was initiated in (1997) was summarily abolished in 2013 with no consultation and with the vague suggestion of a 'Master Teacher' model instead to replace it. Nothing has come of this proposal (Goodwyn, 2016). Of course, there is nothing unusual about such peremptory and undemocratic political decisions affecting teachers, The General Teaching Council (GTC), meant to become the equivalent of the General Medical Council and other similar independent professional bodies, was set up in 2000 and abolished in 2012. The GTC was not popular with teachers (Goodwyn, 2010) and has not been 'missed' but the reason for that unpopularity was principally because teachers felt it had no voice of any significance and was merely a regulatory body not an advocate for the profession that might, when necessary, challenge and resist political impositions. What its demise illustrates is that teaching needs 'voices', perhaps representing different strengths and perspectives. The teacher unions (another global phenomenon) certainly have a key role to play in ensuring that the working conditions of teachers are protected and improved but their voices are limited and they therefore cannot be the sole representation.

This chapter tells the story of the Advanced Skills Teachers (ASTs) drawing on extensive research data with ASTs themselves (see Fuller, Goodwyn, Francis-Brophy, E.\& Harding, 2010, and Fuller , Goodwyn \& Francis-Brophy, E.2012), Local Authority AST coordinators and a range of Senior School Leaders. It gives voice to the experience of ASTs, their passion for teaching and learning, their anger and disappointment at the summary abolition of their hard earned status. It also airs the views of 
Head Teachers and others who were equally concerned about this peremptory policy change. The AST model was not perfect and some of these voices also articulate criticisms of the role and put forward ideas for improvements, should there be a new national model.

The chapter concludes by putting forward a new conceptual framework - drawn from the research and examples from other systems - emphasising the nature of the 'voice' that leading teachers can offer the profession as a whole. It also examines the need to overcome the empty rhetoric of politicians who make much noise about 'world class teachers' but do nothing to develop the profession to achieve such a level. In addition, it addresses the narrow prejudice of the media who often deride these models as 'Super Teachers' (Goodwyn, 2001b). What society needs to be able to hear is the voice of its leading teachers who can be the best advocates for the importance of the teaching profession.

\section{Background and context}

It was a slogan of the 1990s that 'Every Child Matters' and of course that is both true and at the heart of what a decent education system strives to achieve. It is not a contradiction to say, however, that 'Every teacher matters', but that is currently not the experience of the profession in England, where this case study of The Advanced Skills Teacher (AST) is set. Schools in England face a very serious recruitment and retention crisis with many teachers leaving before they complete 5 years in the classroom and many experienced teachers either retiring early or changing careers. There are many suggested solutions to this problem but they tend to be very short term (teacher training bursaries for example). What is really needed is a politically neutral, long term strategy focused on raising the status of the profession and making it much more attractive for bright graduates to sign up, and even more important to keep them becoming increasingly expert practitioners, developing years of cumulatively valuable experience. It will be argued, without any notions of elitism, that certain teachers do matter more to some students and that some teachers can matter more in terms of how they can support and develop other teachers (see the meta-analysis by Hattie, 2003). All teachers matter and some, those that take on an extra level of challenge, may be given a form of recognition that makes them leading voices for all teachers.

England faces a particular crisis but the nature of the issue is global as is established below. One scheme - not a panacea - but certainly a longer term strategy, was the creation of The Advanced Skills Teacher (AST), a project that had great potential to raise teacher's status in comparisons to other top tier professions and to keep the best teachers in the classroom, with better salaries and a career structure that provided recognition and reward both intrinsic and extrinsic. The AST was thus a particular voice for the profession, a high level status to recognise and celebrate the best teachers. 
What can we learn from this story and the fact the role was summarily abolished in 2013 ? As the relatively new Chartered College (established in 2015) for teaching begins its work to create 'Chartered Teacher Status' (for the decision to use the term 'Chartered' see Goodwyn and Cordingley, 2016b) what are the signs of a new voice developing for the profession?

\section{A global phenomenon}

That teachers are generally valued is a global phenomenon. However, it is perhaps ironic, that in what have been called 'high performing jurisdictions' (Moushed and Barber, 2007), teaching is regarded as very much a second tier profession. Certainly this is true of England (Goodwyn, 2001a), but also, for example the USA and Australia. The other increasingly global phenomenon is the establishment of a variety of models of 'expert teaching' in different systems; these systems are increasingly borrowing and adapting models from other systems. This can be briefly illustrated here to set the AST into an international context (for a very detailed characterisation see Goodwyn, 2016).

The first creation of a descriptor for these specially recognised teachers was probably the Advanced Skills Teacher in Australia in the 1970s (Ingvarson \& Chadbourne, 1997). This was a very modest scheme, chiefly involving a minor pay increase and the award of this title to very experienced teachers whom the senior management wished to retain in the classroom (Goodwyn, 2010). A much more substantial scheme was created in the USA in 1988. The National Board for Professional Teaching Standards (NBPTS) was set up to recognise Highly Accomplished Teachers (HAT) ( for an evaluation of its impact see National Research Council, 2008) and its remit was to develop subject specific standards for teachers and then design a credentialising programme. To be awarded this status a teacher has to go through an elaborate process of providing evidence; in summary they have to spend a year developing a substantial portfolio of evidence which includes a video diary and commentary, and also to attend an assessment centre; it is a pass/fail model and the HAT status is for an initial 5 years. The fee is about $\$ 3000$ and most teachers pay for themselves, typically getting the money reimbursed by their school or their state if they pass. The NBPTS is entirely independent and self-funded (for detail see its web site).

Given that the proposed new scheme in England is designed to give Chartered Teacher status, it is important to mention the Scottish Chartered Teacher Scheme. This began with much consensual optimism as the Ministry, the teacher unions and the Universities providing Teacher Education all backed the scheme. However, after 5 years, it was abolished in the same summary way that the AST was abolished in England (for detail, see Goodwyn, 2016). Interestingly, Australia has now moved on from its AST model and has a relatively new organisation, The Australian Institute for Teaching and 
School Leadership (established in 2010: https://www.aitsl.edu.au/) which is working with a new scheme with 4 levels of recognition of teachers: The Graduate, The Proficient, The Highly Accomplished and The Lead Teacher. The global phenomenon is also a phenomenon of borrowing and adapting with the importing of the term Highly Accomplished Teachers from the USA to Australia. In 1997 the Department for Education and Employment (DfEE) in England imported the term Advanced Skills Teacher (AST) from Australia, and the grade was formally introduced in September, 1998. The Chartered College in England, if it is to become a voice for the profession, needs to learn from and adapt ideas from these previous and extant models and schemes.

\section{The Advanced Skills Teacher in England}

Teaching is a modest profession and teachers do not like the term 'expert'. AST generally was a more acceptable term although there was no consultation about its rather sudden introduction. Other terms have been used in England with the government's inspection agency, the Office for Standards in Education (Ofsted) for many years identifying 'outstanding teachers' and there was a scheme meant to run alongside the AST, The Excellent Teacher, but only 57 teachers applied for it and so it never got off the ground (Goodwyn, 2010). It is notable that the Further Education sector in 2017 launched 'Advanced Teacher Status' arguing that :

Advanced Teacher Status (ATS) is the badge of advanced professionalism and mastery in further education and training. It is an advanced professional status that is conferred by the Education and Training Foundation (ETF) through the Society for Education and Training (SET).

This status recognises experienced education professionals who can demonstrate:

- $\quad$ mastery in teaching and/or training

- $\quad$ an exemplary degree of subject knowledge in their area of professional expertise

- $\quad$ effectiveness in working collaboratively to improve teaching standards amongst their peers and within their organisation or network

(ETF, 2018, p.1)

Finally, only 3 years ago the government announced the creation of a National Teaching Service which would 'parachute' 3,000 excellent teachers into the most underachieving schools; this was so unappealing and so unfeasible that it was dropped within a few months.

The genesis of the AST in England was never explained. It was first announced as part of a White paper in 1997 (DFE, 1997) and then the scheme was suddenly launched as a way to recognise and retain the best teachers in the classroom and to pay them on the equivalent to the Leadership scale for undertaking specialist duties. By 2009 when the scheme had matured a substantial document Advanced Skills Teachers: promoting excellence, was produced by the DCSF (Department for 
Children, Schools and Families \{one of the more bizarre descriptors of the Ministry for Education\}) stating that the main purpose of the AST was summarised as:

The distinctive function of the AST grade is to provide pedagogic leadership within their own and in other schools driving forward improvements and raising standards in teaching and learning.

(DCSF, 2009, p.9)

In answer to the question 'What is an Advanced Skills Teacher?' the document states:

An Advanced Skills Teacher (AST) is an excellent teacher who achieves the very highest standards of classroom practice and who is paid to share his or her skills and experience with other teachers. AST posts can be based in all types and phases of maintained schools and normally involve some outreach work. In order to take up an AST post a teacher must first have been assessed as meeting the applicable standards - those standards that are between a teacher's current career stage and AST status

(ibid p.4)

In 2009, just 4 years before the AST scheme, from having been a key role central to system improvement, was suddenly expendable, the document states very clearly the rationale for having this model:

We need to recognise and retain the best teachers. Until the introduction of ASTs, promotion into management was the typical career route for most excellent teachers. The AST pathway offers teachers who want to stay in the classroom an alternative career route with the potential to earn a salary equivalent to that of many leadership posts. Together with the performance threshold, the Fast Track programme and Excellent Teacher status it is widening career progression opportunities and rewards for the best teachers. AST posts concentrate on good teaching and learning and benefit the profession by helping to raise achievements and spread excellent practice both within and beyond the teacher's school. The creation of an AST post can provide a focus for and leadership in the development of teaching and learning across the school as well as the contribution they make to the development of individual colleagues. The AST outreach role also supports networking between schools and encourages collaboration.

This rationale was extended by itemising the impact of the role:

The AST role benefits:

- their own school by retaining their services as a classroom teacher, spreading their excellent practice through the school and building on the good ideas they bring back from other schools;

- $\quad$ other schools through the outreach contribution the AST is able to make and the potential for building collaborative links;

- $\quad$ the Local Authority (LA) by sharing good practice across schools and raising standards overall;

- $\quad$ the AST by broadening experience and providing new challenges;

- $\quad$ the profession by providing another career option;

- $\quad$ pupils and students through the AST's special contribution to raising teaching and learning standards.

At this time there were Standards for Teachers at a number of levels, beginning with initial teacher training (ITT) and Qualified Teacher Status (NQT), but what concerns us here are the Standards for 
ASTs, which, as summarised by the Training and Development Agency for Schools (TDA) $(2007$, p.7) were:-

\section{Professional attributes.}

Advanced Skills Teachers should:

Frameworks

A1 Be willing to take on a strategic leadership role in developing workplace policies and practice and in promoting collective responsibility for their implementation in their own and other workplaces.

\section{Professional skills.}

Advanced teachers should:

Teamworking and collaboration

A2 Be part of or work closely with leadership teams, taking a leadership role in developing, implementing and evaluating policies and practice in their own and other workplaces that contribute to school improvement.

A3 Possess the analytical, interpersonal and organisational skills necessary to work effectively with staff and leadership teams beyond their own school.

However, these specific Standards were not sufficient. A later document (DCSF, 2009, available at http://dera.ioe.ac.uk/12009/7/ast\%20guidance\%20eng\%20web_Redacted.pdf) outlines all the other standards of which there were a total of 28 , falling under three main categories:

- Professional attributes

- Professional knowledge and understanding

- Professional skills

This illustrates just how demanding was the nature of the role. This high demand gave the role authentic credibility to such teachers having a special voice within and for the profession, although that aspect of the AST was never fully developed.

In order to become an AST, teachers had to prepare a portfolio of evidence and then pass a 2 day assessment by an external consultant who observed the teachers and also interviewed senior management, students and parents in order to satisfy the criteria. Any teacher of any age could apply to become one with their Head Teacher's backing. Local Authorities (LAs) were also involved in the recruitment (and later deployment) of ASTS. Initially the funding came from Central Government, so there was nothing to stop a school or a Local Authority having a number of ASTs. Later funding became much more complex and central funding was reduced so some LAs provided it and also some schools.

The scheme was by no means universally approved. The teacher unions were very negative about the role seeing it as divisive and some LAs refused to work with it (See Goodwyn and Fidler 2001). More strikingly the media reacted by characterising the AST as 'Super Teachers' with cartoons of 
them flying in the classroom window. Co-incidentally, but revealingly, a new scheme, launched in Norway in 2017, with which the current author is working, has had exactly the same representation in the media. This media reaction raises an important question about how the public sees teachers. When teachers appear in the national media it is generally for negative reasons, especially sexual scandals and the like. Good stories about teachers will appear in local news but rarely nationally. Unusually, the award of the Global Teacher prize to a teacher from England in 2018, has had significant media coverage but that is hardly representative of the profession (Goodwyn, 2016). Equally, the national awards of various categories of recognition receive brief media attention. What is suggested here is that role models such as ASTs might form a very powerful voice for what is the best in the profession.

After this unpromising start, and over time, the AST role became credible with LAs, with other teachers and the Senior Leaders in schools as the research cited below demonstrates. Although it was never significant proportionally, and there are no official figures, research in 2011 suggested that there were typically about 5,000 ASTs in post in the period $2000-2013$, that was about $1 \%$ of the teacher workforce. The HAT model in the USA is proportionally about the same (Goodwyn, 2016, National Research Council 2008).

\section{Research in the AST role and the views from within the profession}

Given the limitations of space the reporting of this research is necessarily limited but provides much insight into the role and gives some space to the voices of ASTs themselves. There were 3 small scale investigations into the work of ASTs, 2 by Ofsted in 2201 and 2003 (Ofsted) and one by The Centre for British Teachers in 2004 (CfBT). The 3 initial studies were all positive about the value of the, then, new role. The scheme gradually became truly national although again the DfE never provided a clear overview of how many teachers were ASTs, how many had specialisms in which subject or expertise areas, not even how many were secondary or primary focused. As most ASTS were both phase specific and typically had 2 specialisms, for example Secondary Maths and also NQTs or Primary Literacy and Initial Teacher Training, these figures would have given a very interesting data about the range and depth of the AST workforce. This inattention to the AST scheme as a potentially systems changing agency was part of the long term instability of the model. The only large scale work was undertaken by this author and colleagues over a five year period, including a major survey of ASTs in 2010, a follow up of survey with LA coordinators and then qualitative interviews with school senior leaders in 2013 and 2015.

\section{The surveys}


Data were collected using a mixed method research design, through on-line survey and in-depth interviews with ASTs in England. Using a national database of 1,400 ASTs as the sampling frame, ASTs were invited to participate in the study via email. In total, 829 ASTs from across England participated in the online survey, giving an extremely high response rate of $69 \%$. The national survey gave a detailed and authoritative picture of ASTs. A further 40 follow up in-depth telephone interviews were then carried out.

Of those included in the survey, $75 \%$ were female and $25 \%$ male. $40 \%$ of ASTs worked in secondary schools; 33\% in primary and 7\% in special and 'other' schools, for example Sixth Form, Pupil Referral Unit, and so on. All curriculum subject areas were captured in the survey, with science (12\%), English (9.5\%) and maths (9\%) most frequently represented - this replicates the main subject areas for ASTs in the English secondary sector. Significantly $85 \%$ of AST posts were funded by their Local Authority (LA), with the remaining $15 \%$ being funded by their employing school.

The online survey included closed and open-ended questions. Forty ASTs were interviewed using a semi-structured interview schedule that was devised following an analysis of the survey results. Questions addressed the main topics of the survey, focusing on particular examples of support, impact, changes to their status and views on the policy instrument overall. Some chi-square tests of the association between certain key variables, for example whether training was provided between assessment and starting the role and since becoming an AST, were included in the findings. Direct interviewee quotes are used here to highlight key themes in the complex working lives of ASTs. Survey results

\section{Assessment and preparation}

$60 \%$ of ASTs found the assessment process time consuming and, at worst, a frustrating process for a small minority (7\%). More than half of the surveyed ASTs however, felt that the level of assessment 'was about right'. Only a quarter of ASTs received any training before starting their role meaning that most felt ill-prepared. Of this group of ASTs who had training between assessment and starting the role, $91.5 \%$ had additional training since becoming an AST. Even though a small proportion received training early on, they were nevertheless highly significantly more likely than those who did not receive prior training to also go on to additional training $\left(X^{2}(1 d f)=31.482, p<0.000\right)$. How well prepared teachers considered themselves to be, is very significantly associated with training and support $\left(X^{2}(4 d f)=34.530, p<0.001\right)$.

I seem to remember having an hour's chat with the co-ordinator and that was my introduction...I tried to take it as a positive challenge but, in all honesty, it would have been good to have had some training 
Twenty per cent of teachers found out about the AST role for themselves. The $80 \%$ who were directed towards the post were primarily encouraged by their heads, SLT, Ofsted or LA advisors. Proportionally, teachers whose headteacher suggested they become an AST felt the most prepared.

\section{'Being' an AST}

$85 \%$ of respondents enjoyed being an AST 'most of the time', with more than two fifths stating that the role was what they expected it to be. However, almost all ASTs found the role demanding, primarily because of large workloads (24\%) and the amount of time it required (33\%). Levels and perceptions of support varied but primarily centred on practical issues that related to the facilitation of out-reach work and appropriate preparation time. A key focus for the work of an AST was the $20 \%$ of teaching time spent on out-reach. However, issues around timetabling, lesson cover, as well as attitudes of the head and the SLT to the role, had an important impact on how well this requirement was facilitated.

...sometimes I only have one period for outreach and so for me to travel there and then get back for my next lesson means it's just not possible for me to go and do it

(Female, primary)

..how well you are supported in your own school and how your colleagues see you will be very much dependant on the head's attitudes...the first head I had was completely opposed to out-reach so was not supportive. She wanted my focus to be on my own school. My new head is much more behind out-reach and so it is easier

(Male, primary)

A chi-square test indicated a highly significant association between how much an AST enjoyed the role and these levels of support $\left(X^{2}(4 d f)=53.928, p<0.001\right)$. Staff who enjoyed the role least were more likely to consider giving up the post or leaving teaching altogether. In addition, whilst most ASTs reported feeling that their work and skills were appreciated and respected in school, $13 \%$ did not; experiencing either direct negativity from colleagues (15\%) or simple ignorance about the nature of the role (15\%). One commented, for example:

...despite explaining to colleagues, some feel I get paid a high, full time wage for doing less teaching than they do.

\section{Deployment and impact}

It was difficult definitively to outline an ASTs role as much of their work was dependent on Local Authority and school priorities. Its focus could range from 1:1 mentoring support for a struggling teacher, INSET training provision to departments or whole school intervention strategies. Interestingly, just over half of ASTs believed their schools were currently allowing them to make the best use of their skills. In addition, a shift in emphasis over a period of years saw far greater focus on schools in special measures. An example of the kind of comment that was made was: 
...the job isn't what it was when I first started as an AST, it's a lot harder now. I used to go into any school that asked for my support but now it's just the schools on Special Measures...and it's about dealing with either poor teaching or poor leadership...it makes it harder because often they don't want you there, well not at first. It's just a really challenging environment and I guess it's that which makes the role harder than it was.

A fifth of ASTs did not feel they were doing enough out-reach; with $41 \%$ stating they wanted more than they were actually doing. However, based on feedback, teachers were clear they were having an impact, with support of teachers (38\%) and the training provision (31\%) being their biggest contribution as an AST:

...my greatest impact is with NQTs, because they've been successful...from the feedback...they stay in the school

(Female, secondary)

...well, results have gone up, department wise and (when I work with individuals) teaching quality has gone up...from the informal feedback (I get) from teachers

(Female, secondary)

I think I've had a huge impact, not just in the county but nationally. I'm invited to give workshops in schools all over the country and I've had a lot of people come and observe me and I do training with them: deputy heads, new advisors (Male, secondary)

...when you get asked to do things more than once, that feels like they value what I do and get a lot out of it. Some of my work comes as a request from people who have spoken to other people so, it's sort of 'word of mouth'. That feels like a way of measuring impact. The things I organise outside of school time; that are voluntary in terms of attendance, they are repeatedly well attended and people are keen to take part. This is informal evidence to show my role as an AST is effective

(Male, secondary)

Quantifying this 'impact' however, is clearly problematic given the diverse ways that ASTs are deployed and utilised:

I can't generalise on my impact because the role is so varied...and it would depend on how you measure these things

(Female, secondary)

In terms of the government's policy initiative and the key aims behind the introduction of the grade of AST, almost all teachers agreed that the role was achieving what the government intended it to in terms of raising standards and retaining teachers. As one commented:

...all I can say is that I do really think that ASTs are shaping educational policy in the classroom

\section{Feedback}

Feedback to ASTs was not systematic and varied from performance management; evaluation sheets; self-evaluation to informal feedback based on conversations. The research demonstrated that $70 \%$ of ASTs received some form of feedback whilst $30 \%$ received none. Headteachers were responsible for $25 \%$ of the feedback received, SLT and Heads of departments accounted for $22.5 \%$ and LA 
coordinators $39 \%$ of feedback to ASTs. Of those ASTs who received no feedback, $87 \%$ stated they would find it helpful to have some.

I do get feedback ... from my line manager and outreach schools and from the performance management of my role.

(Male, Secondary)

Well I suppose I do... by what teachers and students say

.( Male, Primary)

It is interesting that while $61 \%$ of headteachers suggested the AST role to teachers, only a quarter were a source of feedback for ASTs.

In terms of Advanced Skills Teachers planning to leave the role, only a small minority, some $7 \%$ of teachers surveyed, planned to cease being an AST or leave teaching altogether, largely because they felt unsupported, stressed or disillusioned.

\section{Having Advanced Skills Teacher Status}

Alternatives to the title of 'Advanced Skills Teacher', for example, 'highly accomplished teacher', 'experienced teacher' or 'expert teacher' were preferable to almost $75 \%$ of ASTs. However, over half the teachers agreed that the title summed up well their level of expertise. From interviews it was apparent that the award of advanced skills teacher status confers a sense of professional recognition that is important to teachers, contributing significantly to their sense of professional self esteem and well being:

I got through the assessment process so, I do feel recognised' male, primary ,...you feel you have status, you've got it on paper and they can't take that away from you. There is some pressure that comes with it but, in the end, you've earned it

(female, secondary)

I feel more respected, because of my role (Female, secondary)

...you are not in the same position as a deputy or assistant head but you have a range of knowledge and expertise so, yeah, your colleagues hold you with a certain amount of esteem (Male, secondary)

...It's nice to be recognised, that I take my job seriously (Female, primary)

...I feel recognised and rewarded. Outside of my school I get quite a bit of kudos before I meet anyone. It gives you a head start, which is good. I don't feel I have to prove myself and people trust my word a little bit more (Female, secondary)

... my status has grown and I feel good for it' female, secondary , I know that the parents of my kids like the fact I am an AST, they feel that their children are being taught by an expert and they seem to respect me for it

(Male, primary).

According to the ASTs, the route was achieving one of the government's key aims in that these highly skilled teachers remained in the classroom and benefited other teachers and schools through outreach work. The ASTs in this research were adamant about the need for career challenges and for 
professional development. It remains highly probable therefore, that without this viable alternative to leadership and management those accomplished teachers might well have been lost from the classroom. As already mentioned what the whole scheme lacked was evidence of its value from independent research.

\section{Senior Leader Research Study}

Partly to address this issue of a lack of perspective on the importance of the AST role, The Senior Leaders in Education (SLE) study consisted of 2 rounds of 25 semi-structured interviews with SLEs, 13 in secondary school sand 12 in primary school. The participants in phases 1 and 2 all came from the same schools but 5 participants changed between the two phases. Phase 1 was summer 2013 and phase 2, summer 2015. All interviews were transcribed and extensive field notes were made. The transcripts were analysed to identity significant and generative themes. This was the first qualitative study of the views of SLEs investigating their concerns about the role of their leading teachers. The findings revealed the need for some changes to UK policy and, by implication, the importance of evaluating the current policies of other high performing jurisdictions that operate leading teacher models. It was clear that SLEs remain adamant that a proper national scheme, like the previous Advanced Skills Teacher model, is vital for retaining the best teachers in the classroom and so, ultimately, to raising the standards of student outcomes. What follows is a selection of key findings. They viewed the status of the profession as low, especially compared to 'top' professions (Law, Medicine) and felt that teaching was now an unattractive career for the best graduates, partly because of relatively low pay and very high living costs, especially accommodation in the South. They all had low retention rates in years $2-5$ of teacher careers. They felt there was a constant negative attention from politicians and the media which did not recognise the chronic teacher shortages or the fact of an ageing profession with significant numbers of early retirement.

SLEs considered that some form of 'expert teacher' status remained important to the profession. They agreed that, in the terms of 'impact', ASTs offered value and made a real and significant contribution to teaching and learning, particularly with supporting struggling teachers and broader teaching leadership developments within school. In addition, some felt there was an important element of professional status to employing ASTs and this was something that was valued by parents and the local community. They especially valued the fact that this had been a national scheme, that ASTs were externally assessed and accredited (no SLE favouritism) and that this scheme provided an alternative to a management style career. There was strong agreement that recognising teacher expertise was an important mechanism for teachers who were aspirational and for teacher development. In some schools they had replaced the AST model with their own schemes using a 
variety of terms with 'Leading Practitioner' or 'Leading Teacher' being the most common. They had not approved of the term Master Teacher. However they had deep anxieties about the future health of the profession and its increasingly negative image. They unanimously felt that a combination of negative political and media rhetoric, a recovering economy and the profession's recognition of its increasing performativity and draconian accountability meant that the future best teachers were leaving after a few years and existing ones were leaving early.

In 2015 they were asked about the possible College of Teachers being introduced and whether they welcomed that idea? There were mixed views about a College for Teachers, a third were openly dismissive and cynical, a third liked the idea but doubted it could avoid political interference and a third were profoundly aspirational that this was potentially a huge opportunity to establish a real voice for the profession that might help to make teaching an attractive and respected profession, both the latter groups felt an expert teacher recognition should be part of the remit of the College.

\section{Conclusions and some future prospects: developing a special advocacy voice for the status of teachers}

It is important to reiterate that there was never a proper national evaluation of the scheme or its impact. Given that this was an expensive scheme funded by the tax payer this was poor government work. The AST scheme also lacked a leadership model to manage it - for example an executive committee or some form of trustees etc. In that sense the AST itself lacked a proper voice. Ultimately it meant it could be summarily abolished as there was no substantial evidence that the scheme was fulfilling its potential or benefiting other teachers and students. There is strong message here for the Chartered College of Teaching, or any similar nascent body, to ensure that it collects evidence that its Chartered Scheme is working and that this is independently verified. What that evidence should consist of is a complex question.

A model like the AST could not be 'measured' by a crude relationship to the test results of the teachers themselves or those they worked with during inreach or outreach. What is suggested here is a different conceptual framework aimed at giving teaching higher status and a clearer voice about the value of the profession.

The model must have conceptual internal and external coherence and comprise os at least some of these elements:-

- It must be administered and controlled by a completely independent - politically neutral professional body comparable to other successful such organisations in other jurisdictions.

- Its rationale must be premised on retaining the best teachers in the classroom and it must provide an alternative career structure to management. 
- There must be a quantitative and qualitative, externally validated assessment and selection model which has credibility with the profession not subject to any political interference.

- It must have a set of descriptors (standards is too uniform a notion) that captures the qualitative nature of the role. These descriptors should be subject to regular (perhaps every 3 years) review by a body made up of leading teacher peers, senior leaders, researchers and some international perspectives - no politicians or civil servants will be included.

- It needs a strong support network (local, regional, national, virtual) that provides sustaining camaraderie for the teachers.

- It needs a model of leadership from amongst the teachers themselves with additional support from other experienced professionals.

- Over time it needs to create procedures to generate substantive evidence of the value (not 'impact') of the role. This aspect is very under researched and

\section{External coherence}

There are a number of additional factors that relate to the external coherence and credibility of the proposed model:

- The role must be 'visibly' controlled by an independent, politically neutral organisation. This body itself must have a strong advocacy voice.

- The organisation must be public facing and create an understanding amongst parents and communities of the value of the role; engaging with this work should be part of the remit of all the teachers.

- The body and its selected and accredited 'special' teachers must see 'out reach' as a public facing role, engaging with all forms of media, speaking to young people about becoming teachers, developing stories about helping individual students and families that are meaningful to the public, demonstrating the highest standards of professionalism and ethical caring.

- These teachers need to 'voice' the deep aspirations of the profession and aid its recognition as a top tier profession.

\section{References}

Australian Institute for Teaching and School Leadershiphttps://www.aitsl.edu.au/about-aits| Barber, M, Moushed, M.. (2007)The Mckinsey Report:How the world's best performing education systems come out on top, New York, Mckinsey.

CfBT, (2004). The Work of Advanced Skills Teachers, Report. CfBT, Reading.

DCSF, (2009). Advanced Skills Teachers. Promoting excellence, London: DCFS. Digital Education Resource Archive (DERA)

DFE (1997) White Paper: Excellence in Schools, HMSO. London: pp.48-49.

ETF \& SET. (2018) ATS: Advanced Teacher Status, ETF \& SET, London 
Fuller, C., Goodwyn, A., Francis-Brophy, E.\& Harding, R. (2010) Advanced Skills Teachers: Summary Report, Reading:University of Reading, Reading.

Fuller, C., Goodwyn, A. \& Francis-Brophy, E. (2012) ‘Being an advanced skills teacher: professional identity and status'. Teachers and Teaching: theory and practice. 19 (4) 463-74

Goodwyn, A. and Fidler, B. (2002) Advanced Skills Teachers: The emergence of the role. paper given at the BERA Annual conference, Exeter.

Goodwyn, A. \& Cordingley, P. (2016). 'The Potential of Chartered Teacher Status'. Education Today. 66 (2), 21-44.

Goodwyn, A. (2016). Expert Teachers: an International Perspective. London, Routledge.

Goodwyn, A. (2010). The Expert Teacher of English. London, Routledge.

Goodwyn, A. (2001a). 'Second Tier professionals: English teachers in England'. L1-Educational Studies in Language and Literature. 1 (2), 149-161.

Goodwyn, A. (2001b).' Who Wants to Be a Super Teacher? The Perils and Pleasures of Recognising Expertise in English Teaching'. English in Australia, 129-130, 39-50.

Hattie, J (2003) Teachers make a difference: what is the research evidence? Auckland, University of Auckland

Ingvarson, L. \& Chadbourne, R. (1997) 'Reforming teachers' pay systems: the Advanced Skills teacher in Australia', Journal of Personnel Evaluation in Education, 11, 7-30. National Board for Professional teaching Standards. Washington D.C.

National Board for Professional Teaching Standards - nbpts.org /

National Research Council (2008) Assessing Accomplished Teaching: advanced level certification programme, Washington: The National Academies Press.

Office for Standards in Education (Ofsted) (2001), Advanced Skills Teachers: appointment, deployment and impact, HMI Report, London.

Office for Standards in Education (Ofsted) (2003), Advanced Skills Teachers: A Survey, HMI Report. London.

Taylor, C. And Jennings, S. (2004) The work of Advanced Skills Teachers. Reading: CfBT

Training and Development Agency for Schools (TDA) (2007) Professional Standards for Teachers Advanced Skills Teacher, HMSO, London. 